\title{
OPTIMALISASI PENGELOLAAN PERPUSTAKAAN DESA MELALUI PELATIHAN PERBAIKAN DESAIN INTERIOR DAN VARIATIF KEGIATAN LAYANAN PERPUSTAKAAN
}

\author{
T. Domai ${ }^{1}$, N.L.V. Anggraeni ${ }^{2}$, A.T. Widiyawati ${ }^{3}$, A.P. Galih ${ }^{4}$
}

\begin{abstract}
ABSTRAK
Keberadaan perpustakaan terdekat di masyarakat adalah perpustakaan desa. Perpustakaan desa merupakan salah satu fasilitas pendukung dalam pendidikan dan informasi di masyarakat sehingga menjadi tonggak perkembangan desa. Kegiatan pengabdian masyarakat ini diadakan di Desa Torongrejo, Kota Batu, Jawa Timur. Tujuan pengabdian masyarakat ini adalah untuk meningkatkan pengetahuan dan keterampilan aparatur desa untuk mengelola desain interior dan membuat layanan perpustakaan yang variatif. Setelah layanan masyarakat ini diadakan, perpustakaan desa Torongrejo membuat perbaikan besar-besaran dalam desain interiornya dan jumlah kegiatan yang mereka lakukan.
\end{abstract}

Kata kunci : perpustakaan, perpustakaan desa, desain interior, layanan, badan publik

\begin{abstract}
The nearest exsistance of library in society is village library. Village library is one of the supporting facilities in education and information in society, therefore it becomes a milestone of village development. This community service activity was held in Desa Torongrejo, Kota Batu, East Java. The purpose of this community service is to improve knowledge and skills of village apparatus to manage interior design and to make variative library service. After this community service was held, Torongrejo village library made massive improvements in its interior design and the number of activities they held.
\end{abstract}

Keywords: library, rural library, interior design, service, public institution

\section{PENDAhuluan}

Seiring dengan perkembangan teknologi, informasi merupakan salah satu kebutuhan pokok masyarakat. Masyarakat dituntut untuk semakin cerdas dalam mencari, memilih, mengolah dan menggunakan berbagai informasi di sekeliling mereka. Hal ini berdampak pada semakin vitalnya keberadaan perpustakaan ditengah-tengah masyarakat sebagai bagian dalam membangun peradaban manusia. Perpustakaan merupakan salah satu tempat yang menyediakan akses bahan bacaan, informasi, dan memupuk kegemaran membaca masyarakat. Perpustakaan merupakan sarana penyedia informasi dan pelestarian peradaban manusia yang dapat dijadikan sebagai media pendidikan, penelitian, pengabdian masyarakat, komunikasi ilmiah antar generasi dan lainnya. Perpustakaan ini juga mampu berfungsi sebagai salah satu upaya dalam melakukan kegiatan belajar

\footnotetext{
${ }^{1}$ Dosen Fakultas Ilmu Administrasi, Universitas Brawijaya

${ }^{2}$ Dosen Fakultas Ilmu Administrasi, Universitas Brawijaya, nik_fia@yahoo.co.id

${ }^{3}$ Dosen Fakultas Ilmu Administrasi, Universitas Brawijaya, anitatriwidiyawati7@gmail.com

${ }^{4}$ Dosen Fakultas Ilmu Administrasi, Universitas Brawijaya, auliapuspa@ub.ac.id*
} 
serta memenuhi kebutuhan pendidikan dalam masyarakat melalui program-program literasi informasi.

Salah satu jenis perpustakaan yang keberadaannya dekat dengan masyarakat adalah perpustakaan desa. Perpustakaan desa merupakan ujung tombak layanan perpustakaan yang dekat dengan masyarakat karena berada di lingkungan desa. Perpustakaan desa adalah perpustakaan masyarakat yang menjadi salah satu sarana pendukung dalam hal pendidikan dan informasi masyarakat desa serta menjadi bagian dari peningkatan pembangunan desa. Pembangunan perpustakaan desa diprakarsai oleh pemerintah desa. Pemerintah desa bertanggung jawab terhadap pendirian dan penyelenggaraannya sehingga dapat digunakan sebagai sarana pendukung pendidikan informal masyarakat yang menjadi salah satu bagian dari program pembangunan desa.

Dalam pasal 3 UU No.43 2007 tentang perpustakaan disebutkan Perpustakaan berfungsi sebagai wahana pendidikan, penelitian, pelestarian, informasi, dan rekreasi untuk meningkatkan kecerdasan dan keberdayaan bangsa. Fungsi rekreasi diterapkan dengan menyediakan koleksi yang variatif, kegiatan layanan yang menarik dan tata ruang yang bersifat rekreatif. Diharapkan perpustakaan menjadi tempat yang menarik bagi masyarakat untuk mendapatkan informasi sekaligus mendapatkan hiburan yang edukatif. Terkait hal itulah pengabdian masyarakat ini ditujukan untuk membantu pengelolaan perpustakaan desa agar dapat menjalankan fungsi informasi sekaligus rekreasi melalui pelatihan variatif kegiatan layanan perpustakan dan desain interior sehingga pemustaka merasa nyaman dan dapat memanfaatkan perpustakaan desa lebih optimal.Desain interior merupakan salah satu unsur penting dalam suatu perpustakaan, tetapi pada kenyataannya hal tersebut sering diabaikan karena banyaknya faktor dalam proses pembangunannya.

Pengabdian ini dilaksanakan di desa Torongrejo, salah satu desa yang berada di Kecamatan Junrejo, Kota Batu. Kecamatan Junrejo sendiri terdiri dari tujuh desa. Junrejo memiliki luas wilayah $26,23 \mathrm{~km}^{2}$ dan penduduknya berjumlah 58.000 jiwa. Berdasarkan hasil pengamatan awal, desa Torongrejo belum memiliki personel yang mampu diberikan tanggung jawab untuk mengembangkan dan mengelola perpustakaan desa,, keberadaan perpustakaan desa masih ala kadarnya dengan ruangan yang kecil dan tidak menarik serta belum adanya jenis-jenis layanan yang variatif dalam menarik dan meningkatkan kunjungan ke perpustakaan desa. Terkait hal tersebut maka pengabdian ini dimaksudkan untuk memberikan pelatihan dan pendampingan dalam mendesain ruangan perpustakaan dan pengembangan variasi layanan perpustakaan.

Terbatasnya pengetahuan pegawai Pemerintah Desa mengenai pengelolaan Perpustakaan Desa serta tidak adanya pustakawan yang bekerja pada Pemerintahan Desa, khususnya di Desa Torongrejo, Kecamatan Junrejo, Kota Batu menjadi latar belakang terlaksananya pengabdian ini. Desa Torongrejo, Kecamatan Junrejo, Kota Batu sedang dalam proses untuk mengembangkan Perpustakaan Desa pada seluruh desa di Kecamatan Junrejo. Adapun kendala terbesar dalam pengelolaan Perpustakaan Desa ini adalah terbatasnya pengetahuan mengenai pengelolaan perpustakaan desa, sehingga dibutuhkan pelatihan pengelolaan perpustakaan desa. Adanya pengelolaan perpustakaan desa yang baik sangat menentukan keberhasilan layanan yang diberikan oleh perpustakaan desa kepada masyarakat. Oleh karena itu, dibutuhkan solusi yang tepat untuk mendorong peningkatan kualitas dan keterampilan personel Desa Torongrejo dalam pengelolaan perpustakaan desa melalui pelatihan dalam memberikan layanan perpustakaan yang lebih variatif dan perbaikan desain interior perpustakaan sehinggan pemustaka merasa nyaman dalam memanfaatkan perpustakaan desa.

\section{METODE PELAKSANAAN}




\subsection{Khalayak Sasaran Strategis}

Pengabdian masyarakat yang dilaksanakan di Pemerintahan Desa Torongrejo, Kecamatan Junrejo, Kota batu ini secara garis besar dilakukan melalui sosialisasi dan pendampingan terkait pengaturan desain interior perpustakaan desa dan variatif layanan perpustakaan. Sosialisasi ini dimaksudkan dalam rangka penyampaian gagasan, informasi kepada kelompok sasaran guna mendapatkan pemahaman, pengetahuan dan ikut berpartisipasi dalam pelaksanaannya. Kegiatan ini diikuti oleh 7 orang perangkat desa, 2 pengelola perpustakaan SD dan 2 orang karangtaruna.

\subsection{Pelaksanaan Kegiatan}

Adapun metode yang digunakan dalam kegiatan pengabdian ini adalah 1) Teori. Pemberian pelatihan pengelolaan perpustakaan desa melalui pemberian konsep-konsep tentang mendesain program-program kegiatan dan layanan perpustakaan yang variatif serta konsep-konsep tentang mendesain ruangan perpustakaan agar lebih menarik. 2) Praktik. Untuk menunjang pelatihan pengelolaan perpustakaan desa, maka dibutuhkan sebuah kegiatan pengalaman langsung yaitu berupa praktik. Dengan metode praktik maka peserta mampu melakukan simulasi dan menerapkan apa yang telah dipelajari dalam teori.

\section{HASIL KEGIATAN}

Beberapa materi yang disampaikan meliputi pengertian dan elemen desain interior, jenis-jenis layanan perpustakaan dan variatif program layanan perpustakaan.

\subsection{Desain Interior}

\subsubsection{Pengertian Desain Interior}

Pengertian desain interior dapat dijelaskan bahwa desain interior merupakan perencanaan, tata letak dan desain ruang interior dalam bangunan. Pengaturan fisik untuk memenuhi kebutuhan dasar tempat tinggal dan perlindungan, mengatur panggung untuk mempengaruhi bentuk dari kegiatan, memelihara gagasan dan mengekspresikan ide-ide yang menyertai tindakan, mempengaruhi pandangan, suasana hati dan kepribadian. Tujuan dari desain interior adalah perbaikan fungsional, pengayaan estetika, dan peningkatan psikologis ruang interior. Faktor utama dalam sistem perencanaan interior selalu menitik beratkan pada 3 unsur yaitu, manusia, ruang, dan lingkungan. Ketiga faktor tersebut harus dipelajari dengan baik untuk menciptakan suatu perencanaan desain interior yang lebih mantap.

\subsubsection{Elemen-Elemen Desain Interior}

Elemen-elemen dasar desain membentuk desain interior dalam sebuah bangunan menjadi lebih memiliki nilai, elemen-elemen tersebut adalah ruang, warna, sirkulasi udara, cahaya, dan tata suara. Elemen-elemen tersebut akan membentuk suatu perpaduan yang membuat desain interior suatu bangunan menjadi lebih indah.

\section{a. Ruang}

Pembagian ruang menurut tata ruang atau layout, pembagian ruang menurut tata ruang didasarkan pada daerah prioritas, yaitu membagi ruang berdasarkan fungsi paling utama dari perpustakaan. Daerah prioritas 1 meliputi tempat untuk keluar masuk pemustaka serta kegiatan lain, daerah prioritas 2 adalah tempat koleksi serta ruang baca, daerah prioritas 3 untuk koleksi tua, non buku, serta ketatausahaan, daerah prioritas 4 adalah ruang lain yang tidak termasuk dalam daerah prioritas 
1,2, dan 3. Daerah prioritas tersebut menitik beratkan pada pintu masuk, sehingga daerah prioritas ditata dan diukur jaraknya berdasarkan jauh dekat akses terhadap pintu masuk.

b. Warna

Warna dapat memunculkan kesan positif atau negatif yang mempengaruhi kondisi sebuah ruangan. Oleh karena itu, pemilihan warna yang tepat akan menghasilkan efek yang baik bagi sebuah ruangan. Hal lain yang mempengaruhi pemakaian warna dalam suatu ruangan kerja adalah 1) Orientasi : tujuan dari ruangan tersebut; 2) Climate atau iklim : faktor penting bagi pemustaka, apabila warna ruang tidak sesuai dengan iklim dapat mempengaruhi psikologi dari pemustaka, apabila warna ruang tidak sesuai dengan iklim daerah bangunan tersebut dapat menimbulkan suatu ketidakcocokkan; 3) Aktifitas : dalam mendesain warna suatu ruangan hendaknya melihat aktifitas pada ruangan tersebut, apakah ruangan tersebut ruangan yang sangat ramai dan aktif dipakai atau tidak.

Pemilihan warna ruangan pada perpustakaan memiliki banyak pengaruh psikologis bagi pemustaka. Pemilihan warna pada perpustakaan harus sesuai dengan kondisi perpustakaan, sehingga tidak akan menimbulkan rasa bosan dan ketidakcocokan bagi pemustaka. Seperti halnya warna ruangan, perabot yang ada di dalamnya juga dapat menyesuaikan warnanya dengan warna ruang yang sudah didesain, sehingga terlihat lebih harmonis.

\section{c. Pencahayaan}

Pencahayaan merupakan unsur penting dalam desain interior, pada ruang kerja pencahayaan berfungsi sebagai penerangan dalam melakukan segala aktivitas. Pencahayaan berfungsi untuk memberi efek cahaya dalam suatu ruang ketika ruang tersebut tidak mendapat cahaya alam, atau jauh dari cahaya alam. Merancang pencahayaan sebagai bagian dari desain interior juga harus mempertimbangkan banyak faktor seperti, letak ruangan, warna ruang, cuaca, serta peralatan yang akan dibutuhkan dalam ruangan tersebut. Peralatan lampu merupakan satu kesatuan dengan elektris bangunan. Sumber cahaya mampu memberikan arah, mempertegas batas bidang, atau menjadi garis paling luar suatu bangunan.

\section{d. Sirkulasi Udara}

Sirkulasi udara dalam sebuah ruang sudah mulai menggunakan teknologi dalam pemanfaatannya, salah satunya adalah AC (Air Conditioning) cuaca yang sering berubah dari terik matahari yang menyengat serta terkadang cuaca dingin, menyebabkan suhu ruangan yang juga berubah-ubah. AC dapat dimanfaatkan dalam sebuah ruang untuk menyesuaikan suhu sehingga tetap stabil. Sirkulasi udara juga dibagi menjadi 2 macam, yaitu buatan dan alami.

\section{e. Tata Suara}

Tata suara pada desain interior juga disebut dengan akustik, yaitu segala sesuatu yang berhubungan dengan pendengaran pada ruangan dengan kondisi tertentu yang dapat berpengaruh terhadap mutu bunyi tersebut. Akustik bertujuan untuk mencapai suatu kondisi dengan pendengaran yang sempurna, sehingga terdengar sama dengan aslinya. Penataan suara pada sebuah ruangan menjadi penting untuk dilakukan, terlebih lagi pada perpustakaan. Penataan suara pada perpustakaan merupakan hal yang harus diperhatikan dalam sebuah desain interior, karena perpustakaan merupakan tempat belajar yang harus dijaga keheningannya dari kebisingan di luar perpustakaan untuk kenyamanan pemustaka maupun pustakawan yang ada pada perpustakaan tersebut.

\subsection{Layanan Perpustakaan}




\subsubsection{Pengertian Layanan Perpustakaan}

Salah satu pelayanan publik yang paling menjadi sorotan saat ini adalah layanan perpustakaan. Sebagai salah satu badan publik, layanan merupakan sesuatu yang tidak bisa dipisahkan dalam sebuah perpustakaan. Ada dua macam layanan perpustakaan, yaitu layanan teknis dan layanan pembaca. Layanan teknis adalah layanan perpustakaan yang kegiatannya berhubungan dengan persiapan buku agar nantinya dapat digunakan untuk menyelenggarakan layanan pembaca, sedangkan layanan pembaca perpustakaan adalah layanan untuk memberikan jasa kepada pembaca, yaitu anggota perpustakaan. Perpustakaan dengan koleksi dan fasilitas yang memadai tidaklah bermakna, jika perpustakaan tidak menyediakan layanan bagi pemustaka. Layanan yang minimal harus ada di perpustakaan adalah layanan peminjaman dan pengembalian.

Berbagai macam layanan yang disediakan perpustakaan merupakan asset berharga dalam perpustakaan. Maksudnya adalah perpustakaan tidak akan bermakna bagi pemustaka tanpa adanya layanan. Layanan yang diberikan perpustakaan tujuannya tidak lain adalah untuk mengoptimalkan daya guna perpustakaan agar dapat dimanfaatkan secara maksimal.

\subsubsection{Jenis-jenis Layanan Perpustakaan}

Perpustakaaan sangatlah identik dengan pelayanan, oleh karena itu agar perpustakaan tanggap terhadap kepentingan pemustakanya, maka perpustakaan harus menyediakan bahan-bahan pustaka yang sewaktu-waktu diperlukan. Fungsi layanan perpustakaan tidak boleh menyimpang dari tujuan perpustakaan itu sendiri. Perpustakaan harus dapat memberikan informasi sesuai dengan kebutuhan pemustaka.

Semua layanan yang ada di perpustakaan hendaknya disesuaikan dengan kondisi tenaga perpustakaan dan kebutuhan pemustakanya. Perpustakaan desa juga harus mampu meyediakan layanan untuk membantu meningkatkan kemampuan dan keberdayaan masyarakat desa melalui kegiatan-kegiatan dan variatif program di perpustakaan.

Mengenai program yang seharusnya ada di perpustakaan, Sullivan (2013: 174) menjelaskan bahwa, program dapat dikelompokkan menjadi dua kelompok, yaitu program berbasis bahan bacaan (literature-based) dan program tidak berbasis literatur/ bahan bacaan (Non-literature-based programs).

Program berbasis bahan bacaan (literature-based) memiliki kegiatan membaca pada intinya. Program ini mempunyai kegiatan antara lain Story Hours; Book Discussion Groups; dan Booktalking. Program berbasis bahan bacaan ini adalah yang paling dikenal dan tradisional program perpustakaan untuk anak-anak. Sedangkan untuk program yang tidak berbasis literatur/ bahan bacaan (Non-literature-based programs) berhubungan dengan ideide dan informasi tidak secara langsung terkait dengan kata yang tercetak. Program ini mempunyai kegiatan antara lain Entertainment and Enrichment Programs; Summer Reading Programs; Family Programs and Family Literacy; Serving Special Audiences (Sullivan, 2013:175-176).

Secara keseluruhan peserta kegiatan antusias mengikuti seluruh kegiatan yang ditandai dengan respon yang positif serta keaktifan dalam diskusi. Kegiatan pengabdian ini diakhiri dengan pemberian bantuan buku dan alat peraga permainan interaktif untuk menunjang kegiatan layanan perpustakaan desa.

\section{KESIMPULAN DAN SARAN}




\subsection{Kesimpulan}

Kegiatan pengabdian kepada masyarakat di perpustakaan desa Torongrejo, Junrejo, Kota Batu ini bertujuan untuk meningkatkan pengetahuan dan skill pemerintah desa dalam mengatur desain ruangan perpustakaan serta membuat kegiatan layanan perpustakaan yang lebih variatif. Dengan adanya pelatihan ini telah mampu mengubah cara pandang pemerintah desa sehingga mereka merenovasi perpustakaan mereka menjadi lebih baik. Pemerintah desa juga membuat program layanan yang lebih variatif seperti perpustakaan keliling, bekerja sama dengan sekolah-sekolah sekitar untuk menarik pengunjung mendatangi perpustakaan desa yang telah berubah wajah.

\subsection{Saran}

Perpustakaan desa Torongrejo telah mengalami banyak perubahan, baik dari sisi desain maupun jenis layanan, tetapi selalu ada ruang untuk pengembangan perpustakaan. Salah satunya adalah adanya tempat duduk bagi pemustaka agar lebih nyaman dalam membaca koleksi yang dimiliki oleh perpustakaan desa Torongrejo, serta membuat pelatihan mengenai pertanian yang menjadi mata pencarian utama masyarakat desa yang diadakan oleh perpustakaan untuk variasi kegiatan, karena kegiatan layanan bukan hanya mengenai koleksi tetapi juga pelatihan kepada masyarakat.

\section{DAFTAR PUSTAKA}

Aziz, Azhar Ridwan (2014), Desain pencahayaan buatan pada proses relaksasi pengguna pusat kebugaran, ITB, Bandung. Indonesia.

Menteri Dalam Negeri dan Otonomi Daerah (2001), Keputusan Menteri dalam Negeri dan Otonomi Nomor 3 Tahun 2001 tentang Penyelenggaraan Perpustakaan Desa/Kelurahan.

Sullivan, Michael (2013), Fundamentals of Children's Services $2^{\text {nd }}$ Edition, American Library Association. USA.

Theresia, Meak (2011), Mewujudkan Desa Pintar melalui Perpustakaan Desa. Tersedia di http://www.batukar.info/komunitas/articles/mewujudkan-desapintar-melalui-perpustakaandesa. diunduh tgl 26 Pebruari 2013.

Undang-Undang Nomor 432007 tentang Perpustakaan. 